\title{
СОВРЕМЕННЫЕ ТЕХНОЛОГИИ ПРОВЕДЕНИЯ ОТДЕЛОЧНЫХ И СТРОИТЕЛЬНО-МОНТАЖНЫХ РАБОТ
}

\author{
Успанова А.С., \\ Исмаилова 3.X., \\ Эльмурзаев М.А.
} ГГНТУ им. акад. М.Д. Миллионщикова, г. Грозный

Мир не стоит на месте. Строительная отрасль за последние десять лет изобилует примерами разработки инновационных технологий. Среди них: трехмерная печать конструкиий и даже зданий в целом, гнущийся $u$ самовосстанавливающийся бетон и, конечно, материал будущего, «графен», который призван значительно расширить фантазии архитекторов за счет своей легкости и прочности. В данной статье произведен обзор технологий проведения отделочных и строительно-монтажных работ.

Ключевые слова: современные технологии проведения отделочных работ, современные технологии проведения строительно-монтажных работ, современные технологии контроля качества строительства.

Отмечу сразу, что многие современные технологии вышеуказанных работ имеют тенденцию значительного уменьшения количества рабочей силы на строительной площадке. Следствием тому является «роботизация» многих технологических процессов. Оно и очевидно, ведь машины намного производительнее, им не нужен перерыв, так как они не устают, а только изредка нуждаются в обслуживании. Однако до полной замены человека машиной совсем ещё далеко, хотя имеются значительные продвижения в этой области.

Там, где заменить человека труднее всего, прибегают за помощью к другой отрасли производства. Промышленное производство приводит к усложнению конструкции, но в то же время легкости её монтажа. У такого метода тоже могут быть свои препятствия, одним из которых является потеря уникальности зданий, однако в этой работе мы не будем затрагивать эту проблему [1].

Технология быстрой сборки из стальных модулей и робот-штукатур

В 2010 году китайская компания Broad Sustainable Buildings (BSB) поставила мировой рекорд по скорости строительства. 15-этажный Ark Hotel (Отель Ковчег) был построен всего за 48 часов. Позднее достижения компании пополнились постройками: 30-этажный отель в Чанше за 15 дней и 57-этажный Мини-Скай Сити за 19 дней. Секрет такой скорости заключается в уникальной технологии, разработанной инженерами BSB. Стальные модули заранее изготавливаются на заводе и подобно конструктору Lego собираются уже на площадке. В отличие от стандартных панелей, стальные модули полностью 
оборудованы готовыми инженерными сетями. Скрепление обеспечивается болтами и конструкции полностью подвержены возможностью демонтажа, рис. 1. Прибавьте сюда экологичность, сейсмическую стойкость в 9 баллов, а также упомянутую выше невероятную производительность и вы получите идеальную технологию монтажа сборочных конструкций.

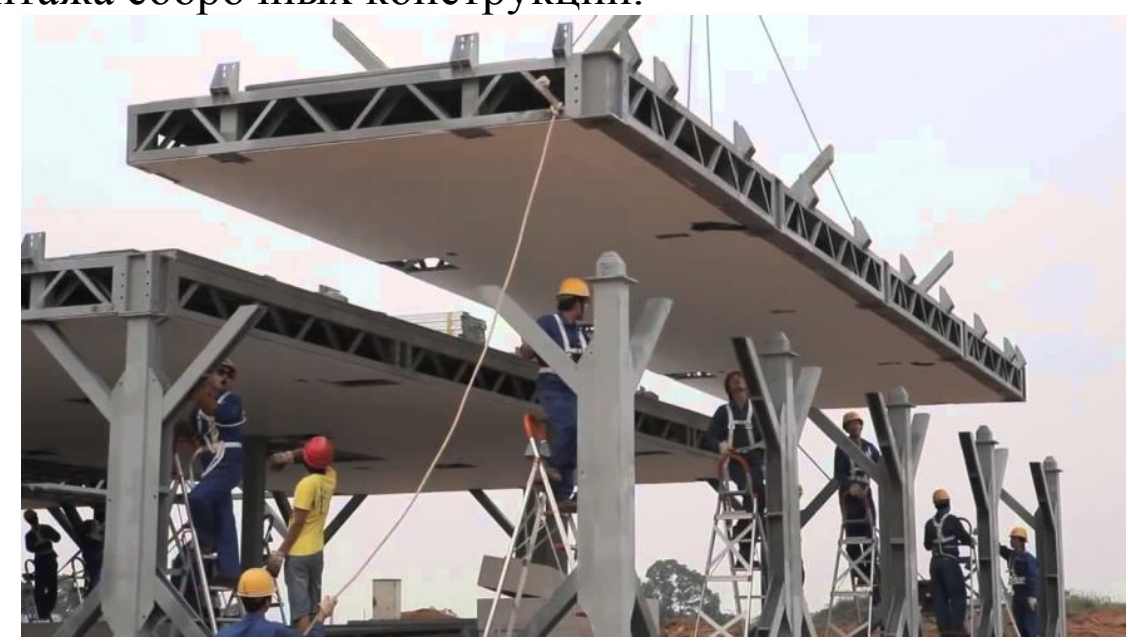

Рис. 1 - Монтаж стальных модулей

Другим примером современных производительных технологий является робот-штукатур для отделочных работ. Известно, что впервые оборудование подобного рода использовалось в Бразилии в начале XXI века. Китайцы подхватили эту идею и немногим позже изобрели более современный вариант данной установки. В России роботы штукатуры впервые появились в 2010 году, а в 2011-2014гг активно использовались при строительстве объектов Зимней Олимпиады в Сочи.

Обычные штукатурные станции примечательны тем, что, после разбрызгивания по стене штукатурной смеси, её приходится выравнивать ручным трудом. У робота-штукатура этот фактор отсутствует. Он одновременно наносит и разравнивает штукатурную смесь, перемещаясь вертикально с помощью гидравлического подъёмника. Человеку остаётся только пополнять бункер новой смесью и передвигать робота в горизонтальном направлении. По средней производительности робот-штукатур обходит стандартную штукатурную станцию почти в два с половиной раза $\left(500 \mathrm{~m}^{2}\right.$ за 8часовой рабочий день), имея при этом высоту нанесения в определенных случаях до 5 метров, рис. 2. Однако такая производительность раскрывается только при больших объёмах отделочных работ, а в иных случаях роботштукатур попросту неэффективен $[2,3]$. 


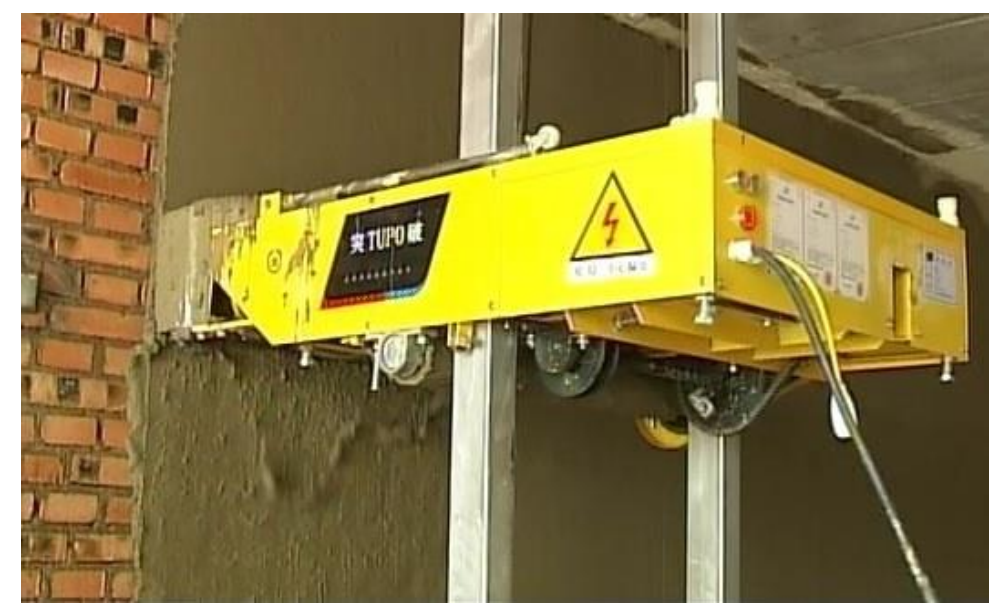

Рис. 2 - Робот штукатур

Технология быстровозводимых мостов и робот Okibo

Технология быстровозводимых мостов разрабатывалась 15 лет в Венском техническом университете и была запатентована ещё в 2006 году. В её основе лежит наличие пустотелых несущих балок, скрепленных верхушками друг с другом и присоединенных к пилону. По мере продвижения строительства балки раскрываются вниз, подобно зонту и в конце заливаются бетоном для придания несущей способности конструкции. Йохан Коллегер из Института структурной инженерии Венского технического университета отмечает, что возведение аналогичного моста с помощью строительных лесов занимает месяцы. В данном случае, на установку сборной конструкции в стартовое положение требуется 2-3 дня, а раскрытие происходит в течение 3 часов. С помощью технологии уже построены два моста через реки Ланбах (100метров) и Лафниц (116метров), рис.3.

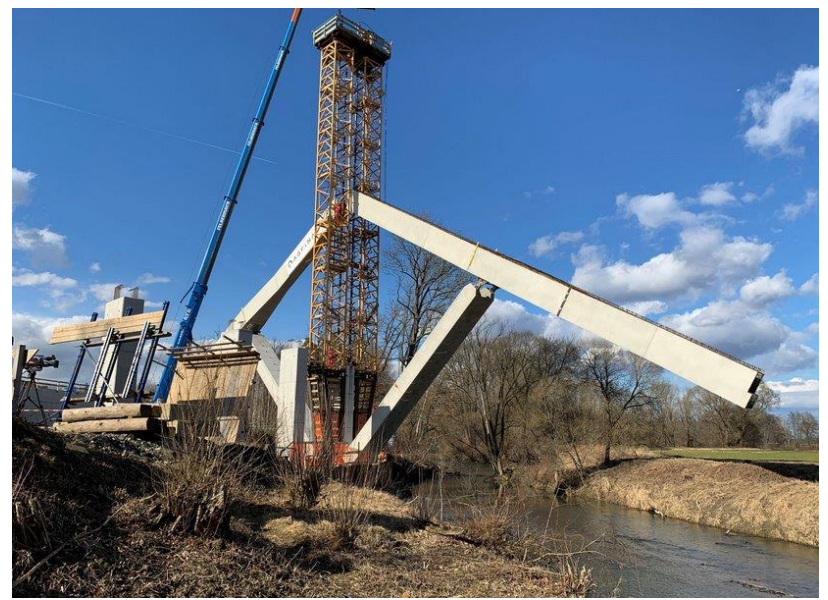

Рис. 3 - Возведение быстровозводимых мостов

Робот Okibo является примером универсальности инновационной техники. Он способен выполнять несколько видов отделочных работ. В зависимости от насадок на основной рабочий орган, он может проводить не только штукатурные, но и лакокрасочные работы. Робот оснащен способностью трехмерного сканирования окружения и полностью автоматизирован. По словам разработчиков, робот намного производительнее человека, рис. 4. 


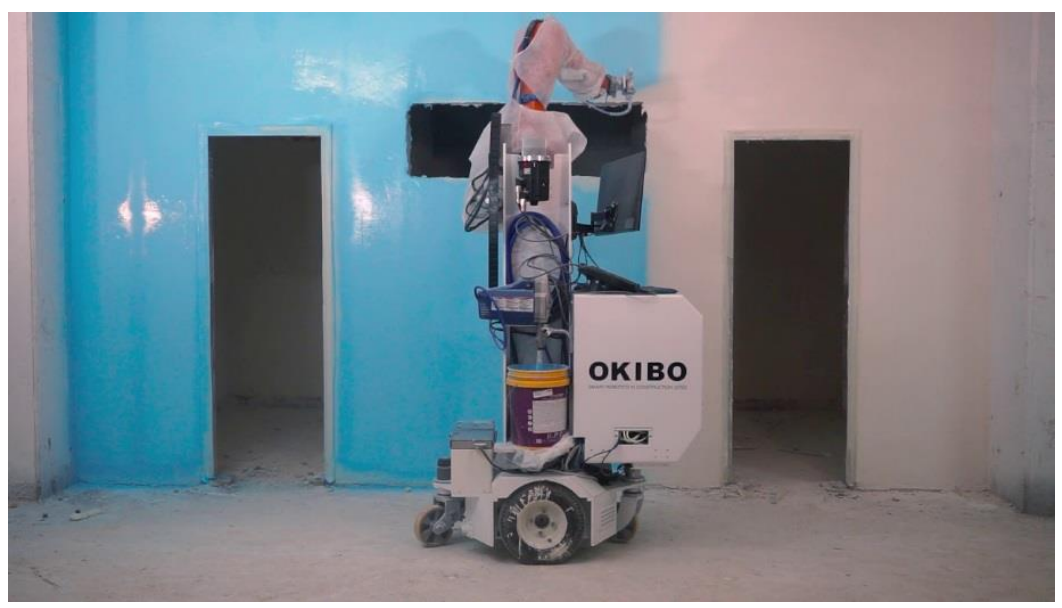

Рис. 4 - Робот Okibo

Экзоскелет Guardian XO и робот HRP-5P

Существует несколько разработок способных перевернуть процесс строительного производства. Одним из них является экзоскелет от компании Sarcos. Guardian XO по сути является роботом повторяющим движения человека. Он позволяет увеличивать прилагаемое оператором усилие в 20 раз. Балка весом в 45 кг покажется легкой - всего 2,2кг, рис. 5. К сожалению, это максимум для одной руки. Полная грузоподъёмность ограничивается весом груза в 90 кг, а скорость движения оставляет желать лучшего. Однако факт того, что подобная техника уже возможна к приобретению и выполняет свои функции, повышает веру в будущее, в котором роль привычных нам подъёмных машин значительно уменьшится [4].
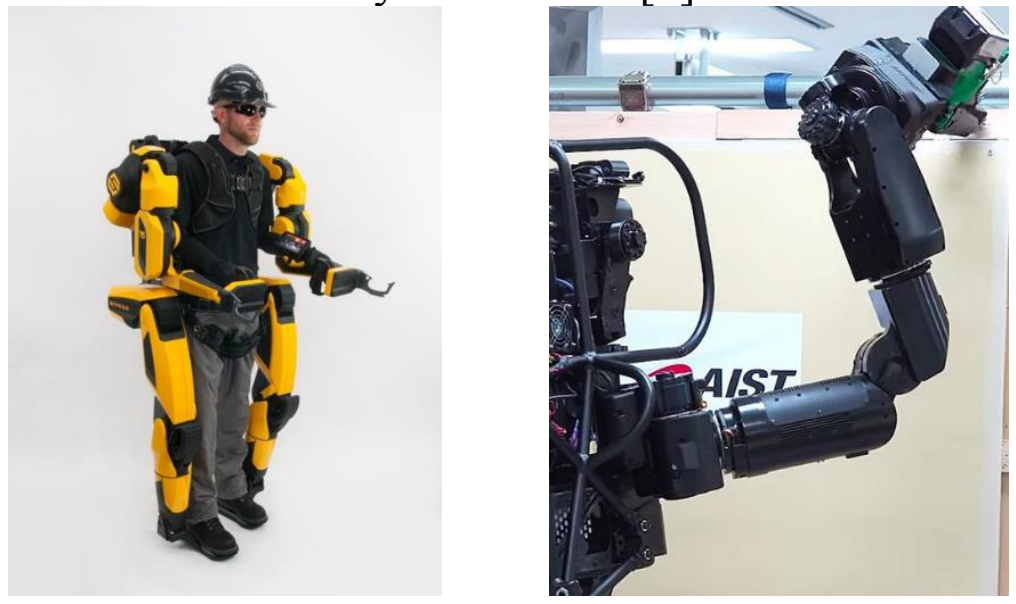

Рис. 5 - Экзоскелет Guardian XО и робот HRP-5P

Робот HRP-5P (P - prototype) является разработкой японского Института передовых наук и промышленных технологий AIST. Он находится на раннем этапе тестирования, но уже способен выполнять монтаж гипсокартона. С помощью камер на голове и ультразвуковых датчиков HRP-5P, хоть и не очень быстро, но с поразительной точностью выполняет заданную работу. По словам разработчиков, монтаж гипсокартона является лишь единственным примером перспективных возможностей робота. 


\section{Современные системы контроля за проведением работ на строительной}

\section{площзадке}

Помимо развития технологий самих процессов, примечателен прогресс в сфере контроля за их проведением. Множество известных, а также только начинающих организаций предложили свои варианты полностью автоматизированной техники контроля за качеством проведения работ [5].

Среди них молодая компания Doxel, имеющая успехи в разработке робота, вооруженного сканером LIDAR. Лазерный сканер позволит собирать огромные массивы данных из окружающей среды, а программное обеспечение, оснащенное искусственным интеллектом и технологией глубинного машинного обучения, будет эти данные успешно обрабатывать. Те же задачи может выполнять всеми известный робот Spot от Boston Dynamics. Он так же оборудован системой машинного обучения и уже выставлен на продажу, рис. 6 .

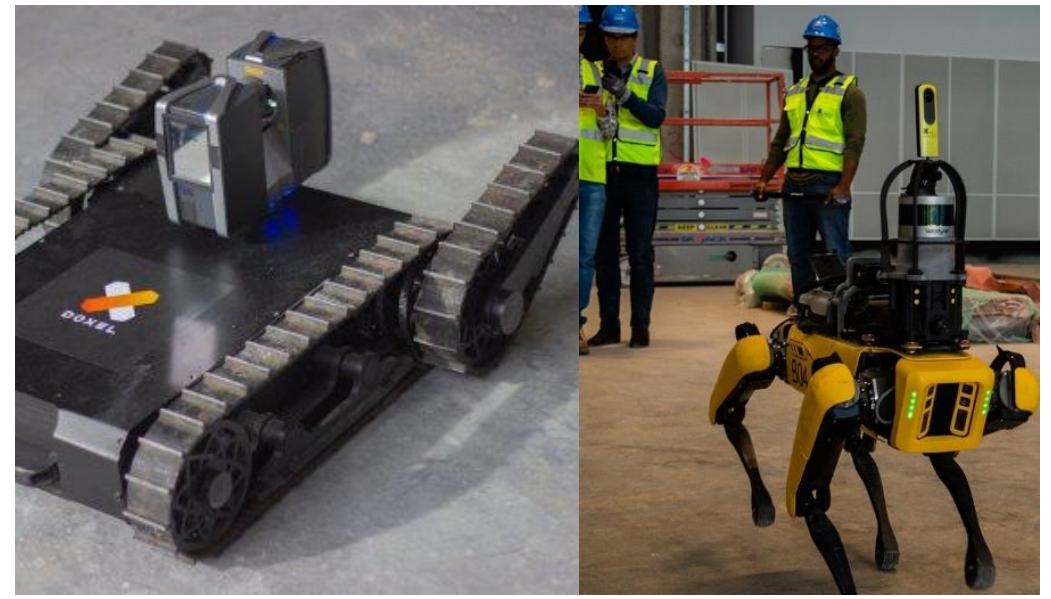

Pис. 6 - Робот от Doxel и робот Spot от Boston Dynamics

Современные технологии проведения отделочных и строительномонтажных работ поражают своей эффективностью, но до полного приспособления их к отрасли ещё совсем далеко. Посему на нас, как на научных деятелей, лежит задача внедрить данные технологии в массовое строительство и в особенности увязать с нашими нормативными документами.

В Чеченской Республике для обеспечения строительно-монтажных работ функционируют несколько заводов по производству сборных конструкций, среди которых особое место них занимают ГУП «Грозненский завод железобетонных изделий» и ГУП «ГЗЖБК», являющиеся основынми поставщиками сборных железобетонных конструкций. Данные заводы способны полностью обеспечить потребность в сборных железобетонных конструкциях на объектах, возводимых в республике. Также на достаточно высоком уровне находится и материально-техническое обеспечение строительно-монтажных работ. Для подачи строительных конструкций в проектное положение в республике применяют передовые строительные краны марки Liebherr. В частности, при строительстве ТРЦ «Грозный Молл» был использован самоходный 500-тонный кран Liebherr LTM 1500-8.1. При этом, при производстве отделочных работ в Чеченской Республике пользуются 
передовыми штукатурными станциями [6.7], которые существенно повышают производительность и снижают сроки выполнения работ.

В целом, стоит отметить, что производство отделочных и строительномонтажных работ на территории Чеченской республики отвечает современным стандартам и представляет несомненный научный интерес для дальнейших исследований.

\section{Исследование выполнено при финансовой поддержке РФФИ в рамках научного проекта № 18-48-200001.}

\section{Список литературы}

1. Ивлиев А.А., Кальгин А.А., Скок О.М. Отделочные строительные работы. М.: Академия, 2000.

2. Электронный pecypc: https://okibo.com

3. Электронный pecypc: https://www.sarcos.com

4. Электронный pecypc: https://www.tuwien.at

5. Никитин А. Фасады: особенности зимних технологий // Стройпрофиль. 2013. № 2 (105). С. 1 -20.

6. Аласханов А.Х. Дребезгова М.Ю. Строительная индустрия и промышленность строительных материалов в Чеченской республике // Материалы международной научно-технической конференции молодых ученых (посвященной 160-летию со дня рождения В.Г. Шухова). - Белгород: БГТУ, 2013. [электронный ресурс].

7. Ботка Е.Н. Рынок сухих строительных смесей России: от спада к стабилизации.// Технологии и бизнес на рынке сухих строительных смесей. 2009. № 10. C. 3-5. 